\title{
MECHANISMS OF BUILDING THE TEXT CONTENTS AND MEANING IN THE PROCESS OF ITS PERCEPTION: PSYCHOLINGUISTIC APPROACH
}

\author{
Nataliya V. Matveeva \\ Sterlitamak Branch of the Bashkir State University, Sterlitamak, \\ Republic of Bashkortostan, Russian Federation
}

\begin{abstract}
The purpose of the article is to investigate the semantic structure of a text with the help of an experimental method. Text meaning and sense are supposed to be the components of the semantic structure. In the article the definitions of the terms "contents", "meaning" and "sense" are given. The term "contents" is used differently from the terms "meaning" and "sense" when speaking about a text. Experimental research, described in the article, proves that there are mechanisms of text meaning formation and sense building which are not the same: preserving or change in the hierarchy of denotates in the contents structure of $\mathrm{T} 2$ in accordance with $\mathrm{T} 1$. We investigated a source text (T1) and produced texts (T2) and analyzed the mentioned above mechanisms. For the research we used such psycholinguistic methods as creating the denotational graph, pointing out themes, subthemes and analysis of denotational and connotational meanings of synonyms in the produced texts. These texts were produced in different ways: in an "active" and "passive" ones. As a result we proved the existence of mechanisms of text meaning formation and sense building as different phenomena and ascertained the necessity of the future research of the individual strategies of text perception by teenagers. The necessity of the further investigation of the individual strategies used in the process of understanding a text is explained.

Key words: contents, sense, meaning, text, mechanism, denotate, graph, connotative synonym.

Citation. Matveeva N.V. Mechanisms of Building the Text Contents and Meaning in the Process of its Perception: Psycholinguistic Approach. Vestnik Volgogradskogo gosudarstvennogo universiteta. Seriya 2, Yazykoznanie [Science Journal of Volgograd State University. Linguistics], 2017, vol. 16, no. 2, pp. 82-92. (in Russian). DOI: https://doi.org/10.15688/jvolsu2.2017.2.8.
\end{abstract}

\section{МЕХАНИЗМЫ ФОРМИРОВАНИЯ СОДЕРЖАНИЯ И СМЫСЛА ТЕКСТА В ПРОЦЕССЕ ЕГО ВОСПРИЯТИЯ: ПСИХОЛИНГВИСТИЧЕСКИЙ ПОДХОД}

\author{
Наталья Васильевна Матвеева \\ Стерлитамакский филиал Башкирского государственного университета, \\ г. Стерлитамак, Республика Башкортостан, Российская Федерация
}

\begin{abstract}
Аннотация. Предметом исследования в статье является семантика текста, составляющими которой выступают содержание и смысл, исследуемые экспериментальным методом. В работе определены понятия «содержание», «значение», «смысл» в аспекте психолингвистического подхода к изучению текста и выдвинута гипотеза о существовании различных механизмов формирования содержания и смысла текста. Материалом исследования послужили исходный текст и вторичные тексты активного и пассивного порождения, созданные реципиентами (подростками 12-14 лет), участвовавшими в эксперименте. В качестве инструментов исследования внутренней структуры текста и механизмов его порождения в статье использованы следующие психолингвистические приемы: построение денотатного графа и анализ денотативного и коннотативного значений синонимов во вторичном тексте.

Анализ результатов проведенного автором статьи психолингвистического эксперимента позволил установить, что механизм формирования содержания состоит в сохранении иерархии в отношениях денотатов
\end{abstract}


в структуре содержания вторичного текста по отношению к структуре исходного текста, а механизмы формирования смысла включают изменение иерархии в отношениях денотатов в структуре содержания вторичного текста по отношению к структуре исходного текста; стратегию использования коннотативных синонимов во вторичном тексте. Обоснована необходимость проведения дальнейшего исследования индивидуальных стратегий, используемых в процессе понимания текста.

Ключевые слова: содержание, значение, смысл, текст, механизм текстопорождения, денотат, граф, коннотативный синоним.

Цитирование. Матвеева Н. В. Механизмы формирования содержания и смысла текста в процессе его восприятия: психолингвистический подход // Вестник Волгоградского государственного университета. Серия 2, Языкознание. -2017. - Т. 16, № 2. - С. 82-92. - DOI: https://doi.org/10.15688/jvolsu2.2017.2.8.

\section{1}

Вопросы изучения текстов различных типов в семантическом аспекте остаются открытыми для обсуждения и привлекают внимание современных ученых разных научных областей. Цель нашего исследования заключается в описании выявленных экспериментальным методом механизмов формирования содержания и смысла текста, что позволит изучать семантику текста в широком понимании этого термина.

Ключевыми для нашего исследования являются понятия «содержание», «значение» и «смысл». Термин «содержание» применительно к тексту имеет употребление, отличное от «значения» и «смысла». В понимании содержания текста мы опираемся на концепцию семантики текста А.И. Новикова, в соответствии с которой содержание речевого произведения как мыслительного образования соответствует его внешней форме в целом, является своего рода значением текста и составляет его семантику [Новиков, 1983]. Таким образом, под семантикой (значением) текста понимается его содержание в отношении к средствам выражения этого содержания. Обозначая предметом исследования содержание и смысл текста, мы учитываем его сложность, обусловленную тем, что «значение текста как единицы речи представляет собой такое ментальное образование, которое не может быть зафиксировано предварительно в словаре, как это происходит со словом. Оно формируется в сознании реципиента при восприятии текста в результате его понимания каждый раз заново» [Пешкова, 2015, c. 70]. С нашей точки зрения, содержание не совпадает со смыслом текста, последний - более широкое образование, включающее помимо содержательного компонента такие компоненты, как эмоциональный, субъективно-оценочный, прагматический и т. д. Н.И. Жинкин предложил определение смысла, которое нам представляется наиболее полным и точным. В соответствии с этим определением смыслом будем называть «такой информационный ряд, который может быть преобразован в ряд синонимически заменяемых слов, но сам не является рядом слов, и такой, который ограничивает информацию определенными рамками, в пределах которых начатый ряд может быть продолжен. Так как слова могут быть преобразованы в смысл и наоборот, то смысл - это код. Минимальная единица смысла перекодируется в два слова, про которые говорят, что они связаны по смыслу» [Жинкин, 1964, с. 28-31].

По мнению А.И. Новикова, смысл, будучи явлением экстралингвистическим, может иметь различные формы выражения, в том числе и невербальные. Следовательно, можно считать, что «область его существования значительно шире языка и потому смысл не равен ему, в то время как естественный язык равен смыслу в том отношении, что всякое выражение языка должно быть осмысленным. Смысл управляет отбором и распределением языковых средств при создании речевого произведения, он же является целью, средством и результатом его понимания» [Новиков, 1999, с. 45].

Принадлежность смысла текста сознанию участников коммуникации означает, что формализация смысловой структуры речевого произведения и ее моделирование предполагают обращение исследователя не только к содержанию текста, но и к смысловой структуре личности, включающей функциональные единицы иного плана по сравнению с единицами содержательной структуры текста [Пешкова, 2015, с. 71], что и обусловило использование эксперимента как основного метода в нашем исследовании. 
2

При проведении экспериментального исследования, которое нацелено на выявление механизмов формирования проекции текста (содержания исходного текста) и механизмов смыслообразования в процессе понимания текста реципиентами, мы исходили из предположения о существовании различных механизмов формирования содержания и смысла [Пешкова, Матвеева, 2003, с. 121-125], одновременно работающих при понимании текста.

В эксперименте приняли участие 200 человек - обучающиеся среднего и старшего звена средней школы в возрасте от 12 до 16 лет, находящиеся на уровне активного формирования языковой и лингвистической компетенций.

Материалом исследования являются исходный учебный текст научно-популярного жанра на русском языке (Т1), предъявляемый реципиентам в письменном виде, и вторичные тексты (Т2), созданные реципиентами на основе исходного. Используя терминологию Ю.Н. Караулова, мы можем говорить об «активном» и «пассивном» порождении Т2 [Караулов, 1987, с. 79]. Активным порождением Т2 можем считать любое порождение, основанное на содержании T1, с привлечением внутритекстовой импликации. Пассивным порождением будем считать порождение по заранее заданной модели (план, алгоритм воспроизведения и т. д.). Полученные в результате эксперимента тексты сравнивались с исходным текстом для установления их содержательной идентичности / содержательного различия. Таким образом было верифицировано предположение о том, что именно активное порождение вторичного текста позволит наблюдать механизмы смыслообразования, а пассивное порождение - формирование содержания.

Одним из инструментов психолингвистического эксперимента служит денотатный граф, позволяющий вербализовать внутреннюю структуру текста, представляющую собой содержание данного текста. Методика денотативного анализа текста, предложенная А.И. Новиковым, позволила сравнить денотатный граф Т1 с построенным денотатным графом Т2 для исследования структуры содержания Т2 и выявить работу механизма перецентровки ситуаций в тексте, позволяющей сделать вывод о понимании / непонимании текста в целом.

Рассмотрим данную экспериментальную методику подробнее. Содержание текста - это целостная структура, состоящая из дискретных элементов, находящихся в определенных отношениях. Оно «характеризуется целостностью, но в отличие от смысла, оно структурно, так как в нем можно выделить дискретные элементы и отношения между ними» [Новиков, 1983, с. 33]. Следуя концепции текста А.И. Новикова, за единицу структуры содержания мы принимаем денотат как динамическую единицу речи, возникающую в мышлении, за которой стоит предметная действительность [Новиков, 1983, с. 47].

Под денотатом может пониматься любой предмет, процесс, явление действительности, составляющие содержание языкового выражения, называемые средствами языка. Он не задан как лексическое значение, а устанавливается и определяется каждый раз в результате осмысления языкового выражения. На поверхностном уровне это может быть слово или сочетание слов. Отраженная в мышлении в результате понимания текста совокупность денотатов представляет собой мыслительное образование, соответствующее его содержанию. Образованная структура определяется связями денотатов между собой. Эти связи задаются отношениями, существующими между объектами реальной действительности, то есть предметными отношениями. В денотатной структуре каждый ее компонент - денотат - занимает свое место в соответствии с иерархическим принципом организации, это место может соответствовать теме, подтеме, субподтеме и микротеме. Формируется денотатная структура в интеллекте адресата в результате полного и глубокого понимания и осмысления содержания сообщения. Она включается в общую систему содержания мышления, дополняет, изменяет его, воздействует на него определенным образом.

\section{3}

Одним из механизмов смыслообразования, по нашему мнению, является изменение иерархии тем, подтем, субподтем в денотат- 
Н.В. Матвеева. Механизмы формирования содержания и смысла текста в процессе его восприятия

ном графе вторичного текста по сравнению с первичным. Для анализа механизма перестройки иерархии структуры содержания была проведена работа по сравнению построенных графов, соответствующих содержанию вторичных текстов Т2, с контрольным графом первичного текста. При построении контрольного графа, были выделены все темы, подтемы, субподтемы и микротемы, учтены все вершины, связанные с несколькими подтемами, субподтемами (рис. 1; здесь и далее главная тема обозначена полужирным курсивом, подтемы даны в прямоугольниках, субподтемы - в овалах, микротемы - в шестиугольниках; стрелки и ли- нии показывают отношения между темой и подтемами, подтемами и субподтемами). Подтема, реализованная в тексте, представляет собой определенную последовательность слов, внутренне связанных между собой в единое целое и составляющих некоторый отрезок текста. Совокупность подтем, включающих свои субподтемы и микротемы и раскрывающих различные аспекты основного предмета описания, заданного замыслом, составляет текст.

С целью выявить действие механизмов смыслообразования, нами был произведен анализ структуры содержания вторичных текстов в сравнении с контрольным графом.

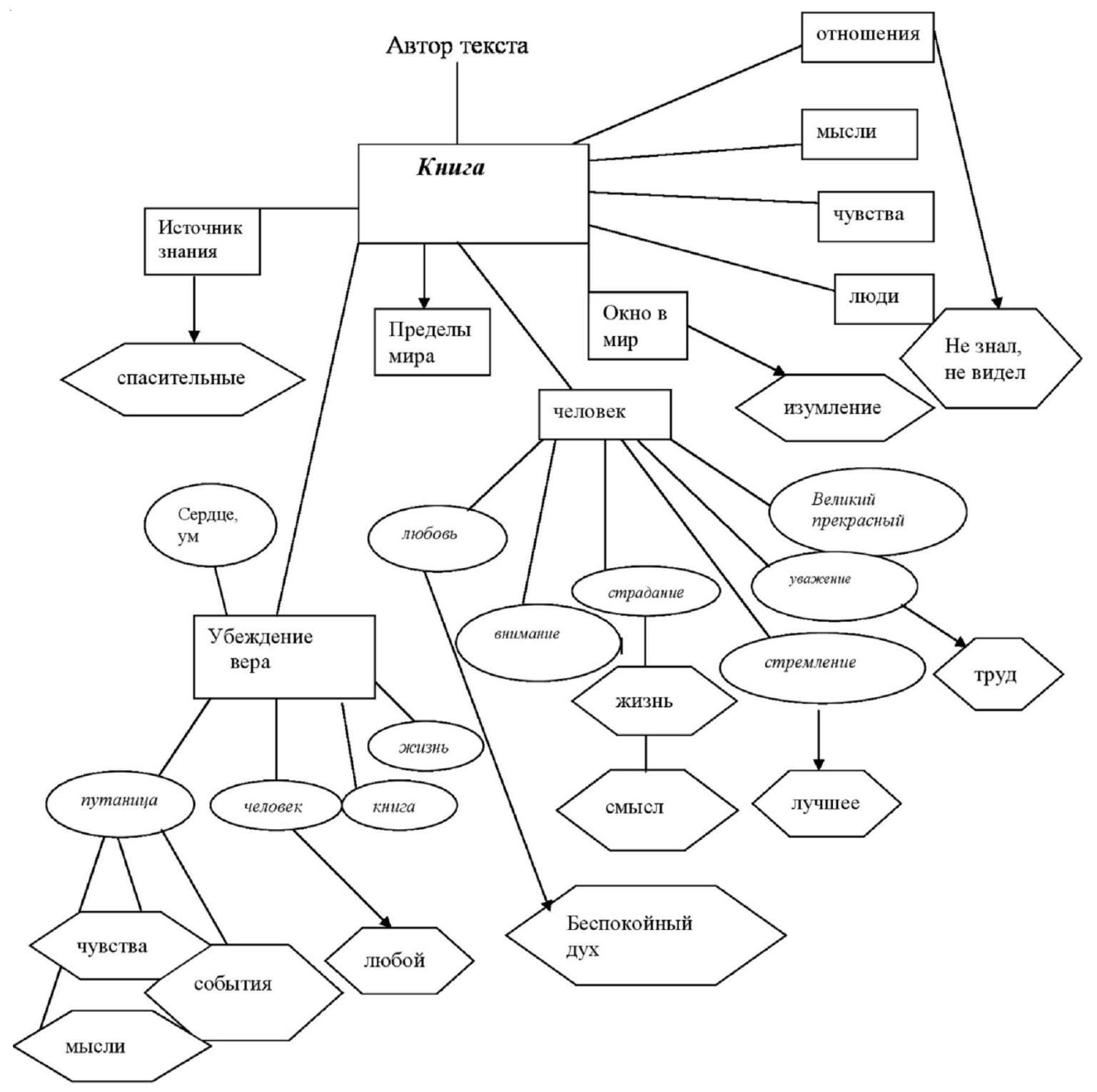

Рис. 1. Контрольный граф структуры содержания первичного текста 
3.1. Графы вторичных текстов пассивного порождения отражают следующую структуру: тема, которая осталась неизмененной, подтемы, субподтемы. В графе 1.1 (рис. 2) тема остается неизменной, подтемы выделены не все, подтема «человек» перешла в субподтему, из трех микротем субподтемы «путаница» выделена лишь одна - «мысли». В графе 1.2 (см. рис. 3) многие подтемы не отражены. Из восьми основных подтем выделены пять, но сохранены все субподтемы. Ни одна микротема не обозначена. В графе 1.3 (см. рис. 4) замещение происходит на уровне подтем. Из восьми подтем шесть представлены во вторичном тексте, вместо двух остальных выделена одна, не отраженная в исходном тексте. Субподтемы представлены лишь в одной подтеме, микротемы отсутствуют.
Основная тема первичного текста не была изменена ни в одном вторичном тексте, следовательно, при пассивном порождении текста она была понята всеми испытуемыми. Однако на уровне подтем, субподтем и микротем наблюдаются изменения (см. таблицу 1, в которой в процентах от общего количества вторичных текстов пассивного порождения указано количество вторичных текстов с сохранением иерархии исходного текста). На уровне подтем эти изменения незначительны (большинство текстов сохраняют иерархию исходного текста: 88 \%, 67 \% и $88 \%$ в разных графах). На уровне субподтем и микротем изменения значительны, они связаны в первую очередь с полнотой раскрытия темы (не все субподтемы и микротемы получили раскрытие), однако искажения содержания текста не наблюдается.

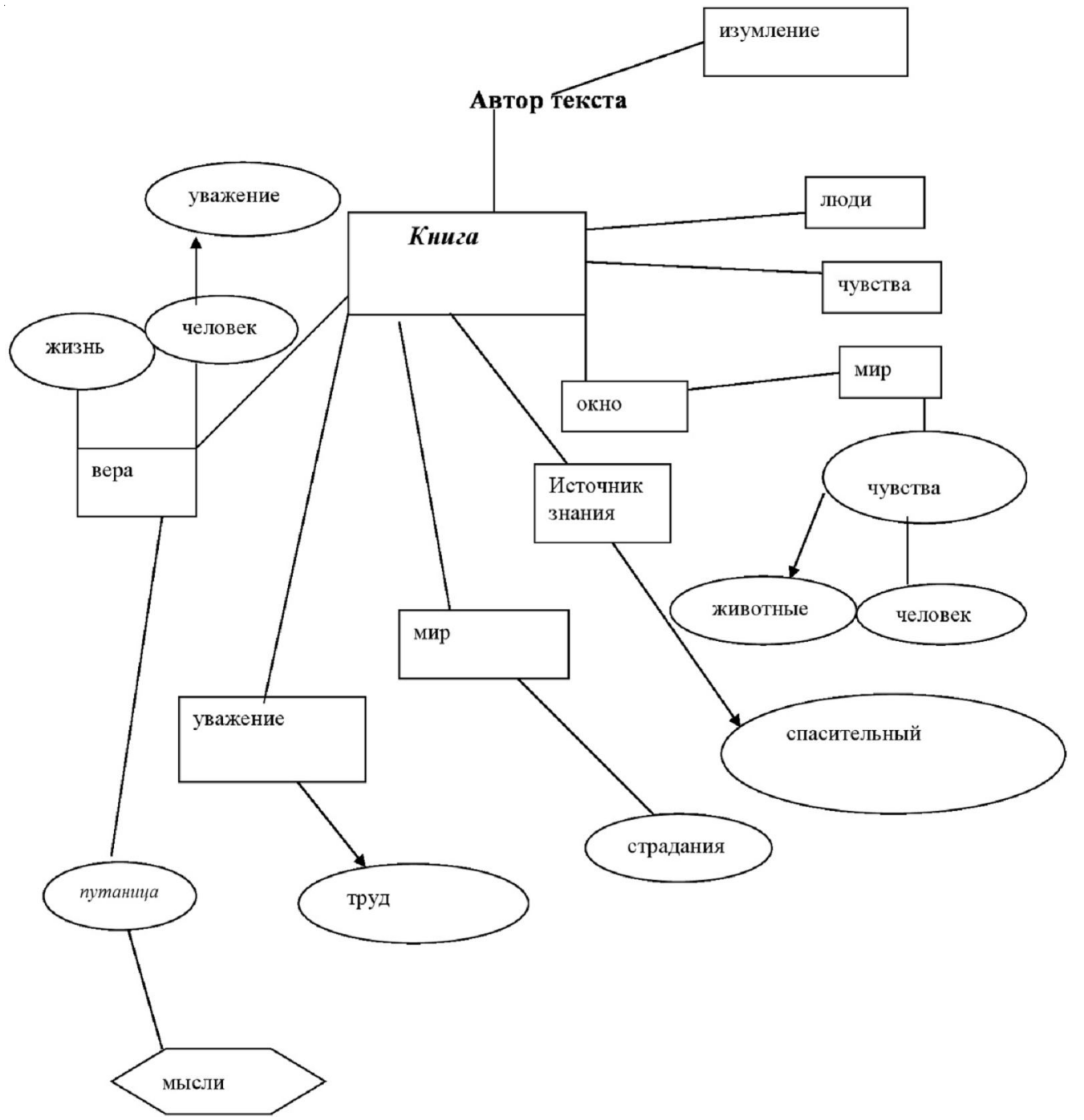

Рис. 2. Граф № 1.1 
H.В. Матвеева. Механизмы формирования содержания и смысла текста в процессе его восприятия

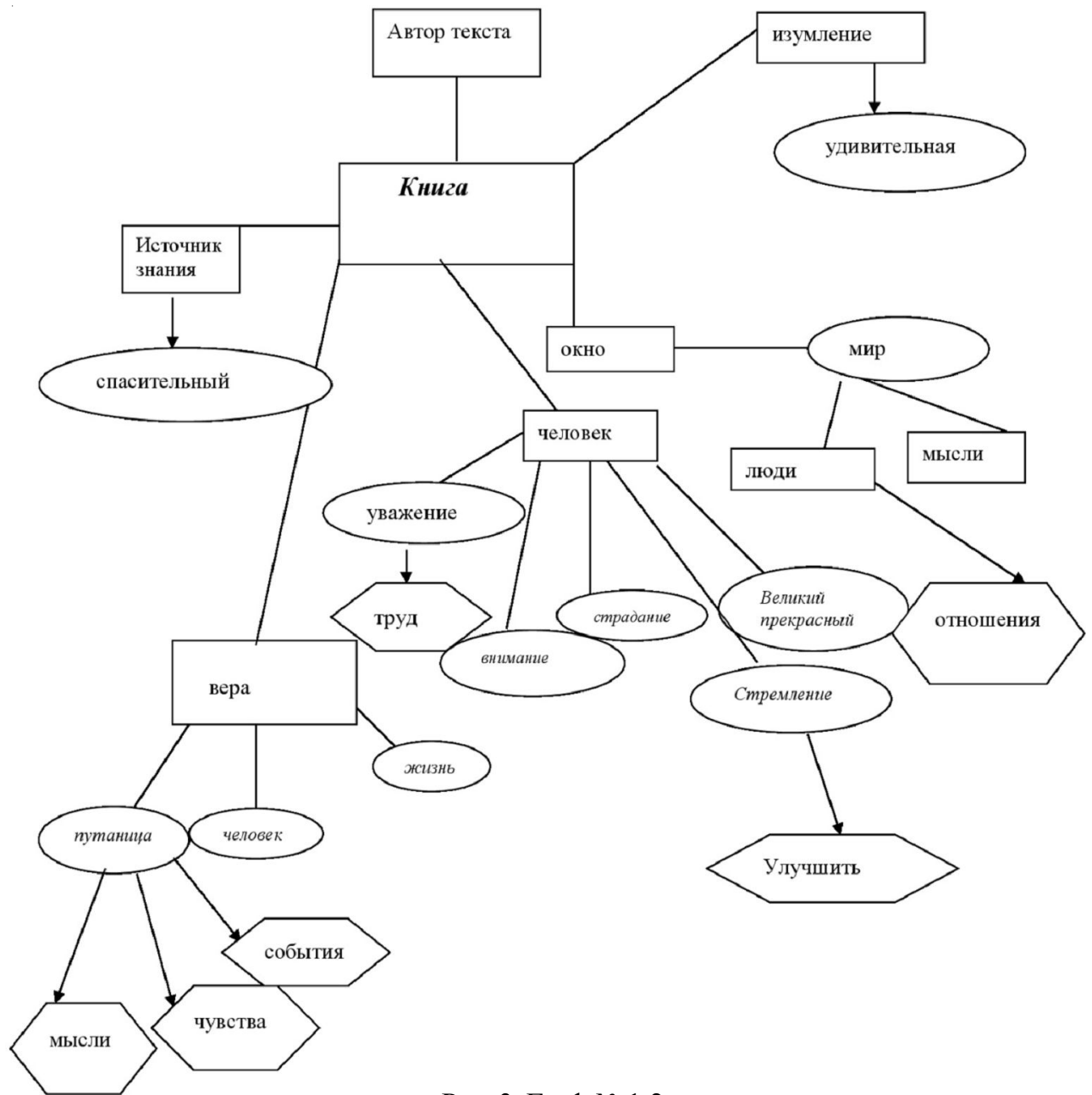

Рис. 3. Граф № 1.2

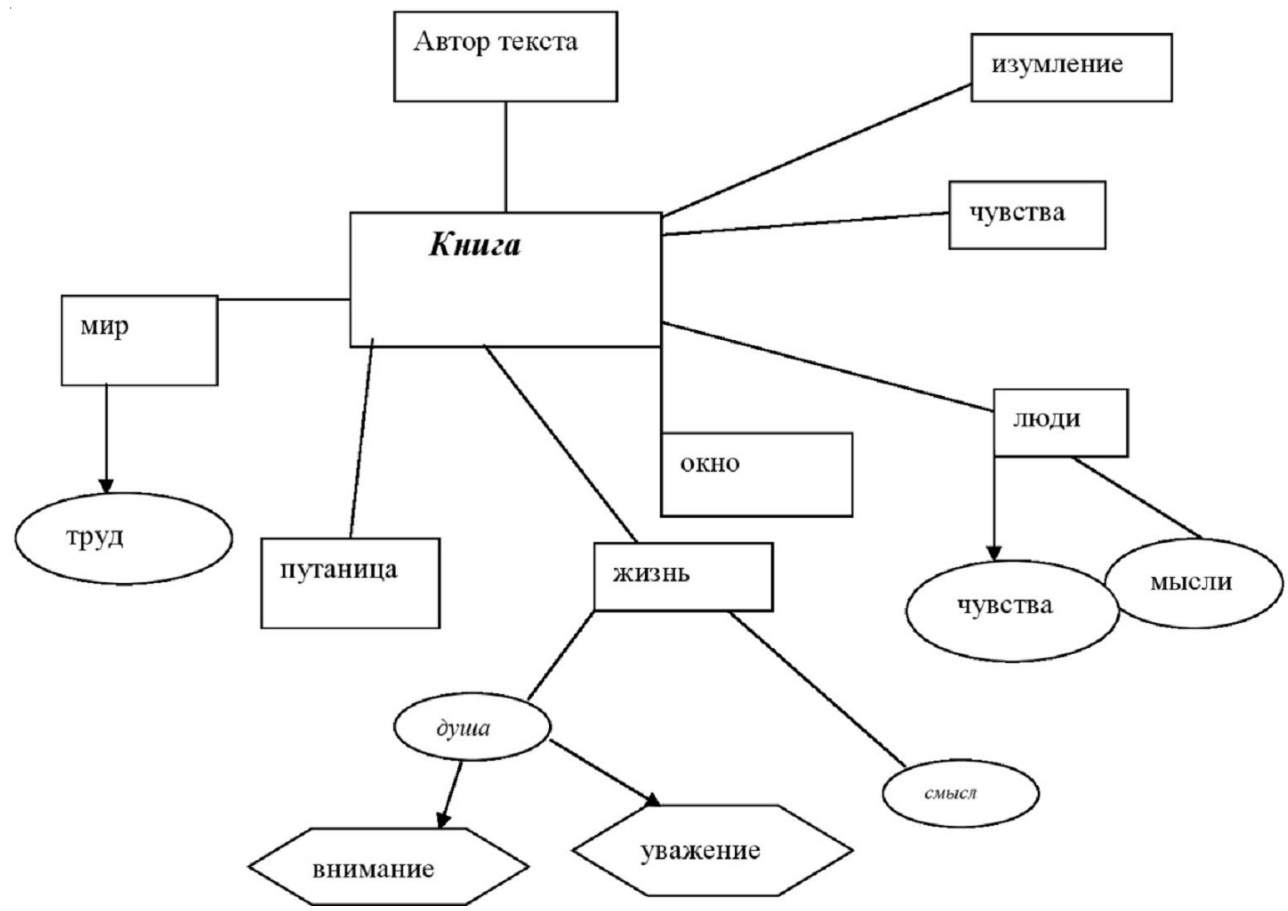

Рис. 4. Граф № 1.3 
Количественная характеристика вторичных текстов пассивного порождения

\begin{tabular}{|c|c|c|c|}
\hline № выборки графа & Граф & Граф & Граф \\
\hline Уровень структуры текста & 1.1 & 1.2 & 1.3 \\
\hline Уровень подтем & $88 \%$ & $67 \%$ & $88 \%$ \\
\hline Уровень субподтем & $45 \%$ & $64 \%$ & $18 \%$ \\
\hline Уровень микротем & $20 \%$ & $20 \%$ & $0 \%$ \\
\hline
\end{tabular}

3.2. Графы вторичных текстов активного порождения свидетельствуют о действии иного механизма смыслообразования: по всей выборке прослеживается изменение иерархии во внутренней структуре содержания. Приведем несколько примеров вторичных текстов (грамматика, орфография и пунктуация источника сохранена) и соответствующих им графов.

\section{Текст 2.1}

Я, наверное, не смогу передать мои чувства, мысли. Я был изумлен, когда я почувствовал, что книга как бы открывает передо мною окно в новый, совершенно другой мир. Я узнал о людях, их чувствах, мыслях и отношениях, которых я не знал, не видел.

Книга рассказала мне о жизни людей, о том как много создал человек, как обустраивал свою жизнь, и хотел стать лучше.

Постепенно я стал внимательнее к людям, стал больше уважать человека. Передо мной открылся новый мир.

Любите книгу - источник знания!

Текст 2.2

Книга открывает мне окно в мир фантазии и вымысла. Книга учит меня уважать человека за его труды. Книга как бы окрыляет чувства и мысли людей. И я говорю: любите книгу. Она поможет вам в жизни, учебе.

Книга научит вас уважать себя и других людей. Из книги вы узнаете много нового и полезного.

Любите книгу! Книга - источник знания, она сделает вас духовно богатыми.

Текст 2.3

Вы не можете представить, каково было мое изумление, когда я узнал о возможностях книги. Она может выражать чувства, рассказывать о людях, делать мир понятным. С помощью книги я узнал, как велик и разумен человек, какие подвиги он совершил, какие чувства пережил.

Книга мне понять и испытать уважение к людям. Я почувствовал их переживания, радовался и огорчался вместе с ними. Книга рассказывала мне о таких чувствах, о которых я не знал.
Любите книгу! Книга - это источник знаний, только знание спасет нас в жизни.

В графе 2.1 (см. рис. 5) тема и ряд подтем раскрыты по отношению к исходному тексту. Субподтемы «страдания» и «любовь» рассмотрены на уровне подтем. Углубления на уровень субподтем и микротем не выявлено в данном вторичном тексте.

В графе 2.2 (см. рис. 6) также наблюдается перестройка иерархии на уровне субподтем, которые звучат как подтемы, например отмеченная субподтема «уважение». Уровень микротем не реализуется. Тема отмечена верно.

В графе 2.3 (см. рис. 7) отмечены все 4 уровня содержательной структуры, хотя углубление получила лишь подтема «мир», которая не была выделена в контрольном графе. Во вторичном тексте 2.3 эта мысль автора, выделенная нами как тема, прозвучала как подтема и получила развитие на уровне субподтем и микротем. Из 9 подтем контрольного графа в этом графе указано 5 .

Таким образом, при активном порождении вторичных текстов происходят следующие изменения в их содержательной структуре: многие субподтемы стали подтемами; микротемы раскрыты в единичных вторичных текстах. Видимо, это объясняется тем, что, восприняв исходный текст, реципиенты старались «ухватить» самую суть, «ключевые» моменты содержания текста и, не скованные планом передачи содержания, свободнее показали свое отношение к теме текста. Часто обнаруживается расширение на уровне подтем, но почти не представлено углубление на уровне субподтем и микротем. Во вторичных текстах появляются и новые вершины, «сигнализирующие» о новых элементах смысла.

Количественная характеристика перечисленных изменений отражена в таблице 2. 
Н.В. Матвеева. Механизмы формирования содержания и смысла текста в процессе его восприятия

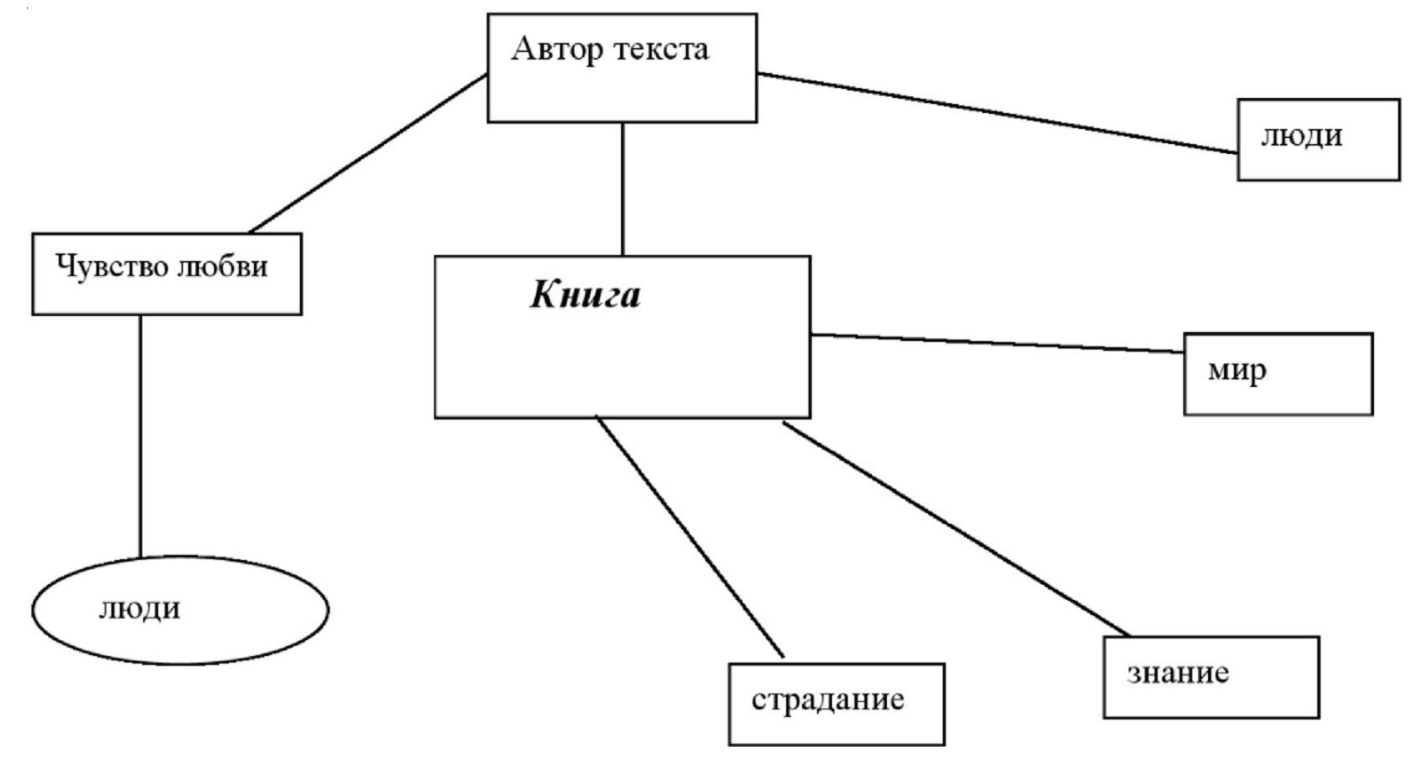

Рис. 5. Граф № 2.1. Денотатный граф вторичного текста активного порождения

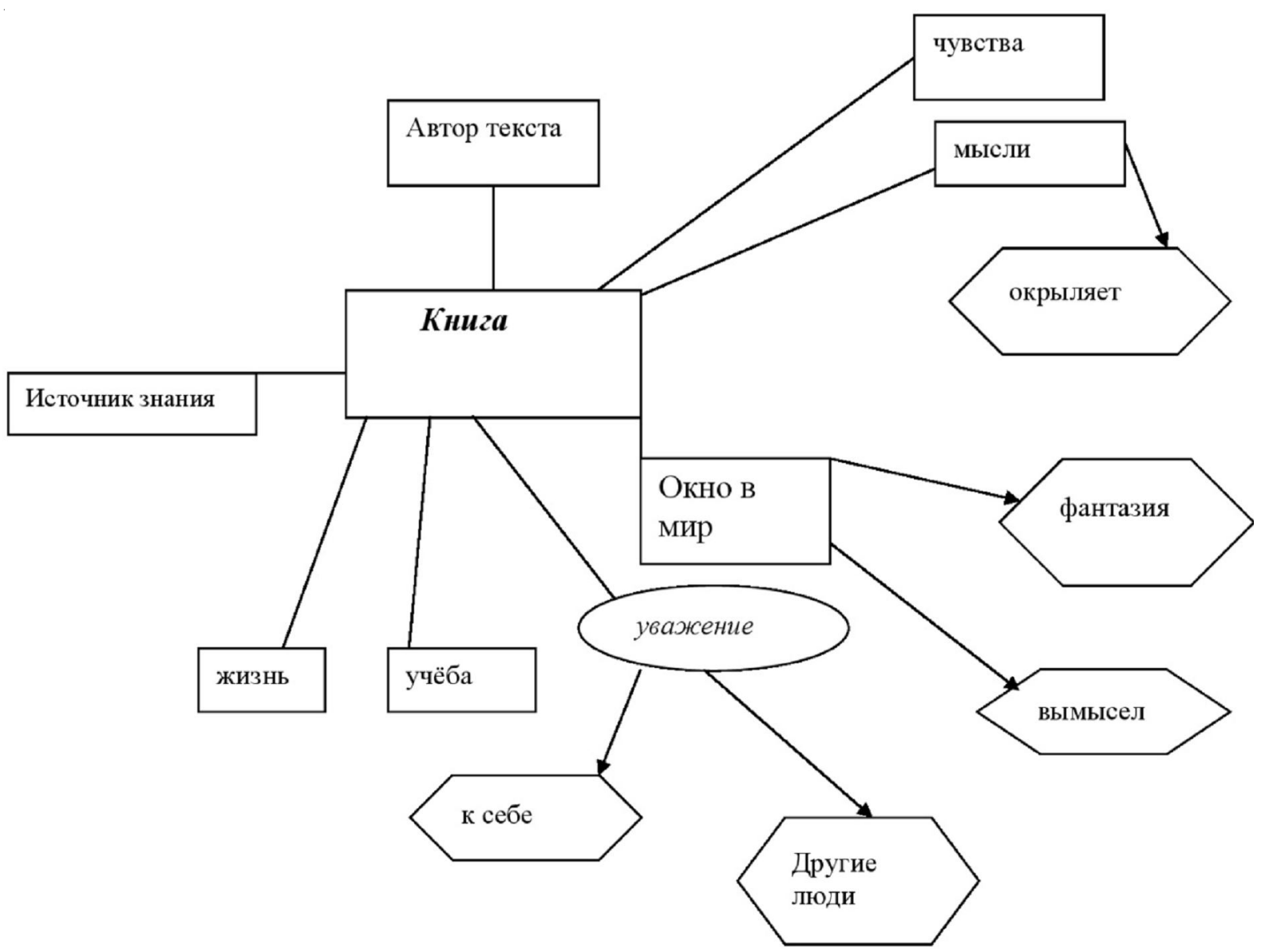

Рис. 6. Граф № 2.2 


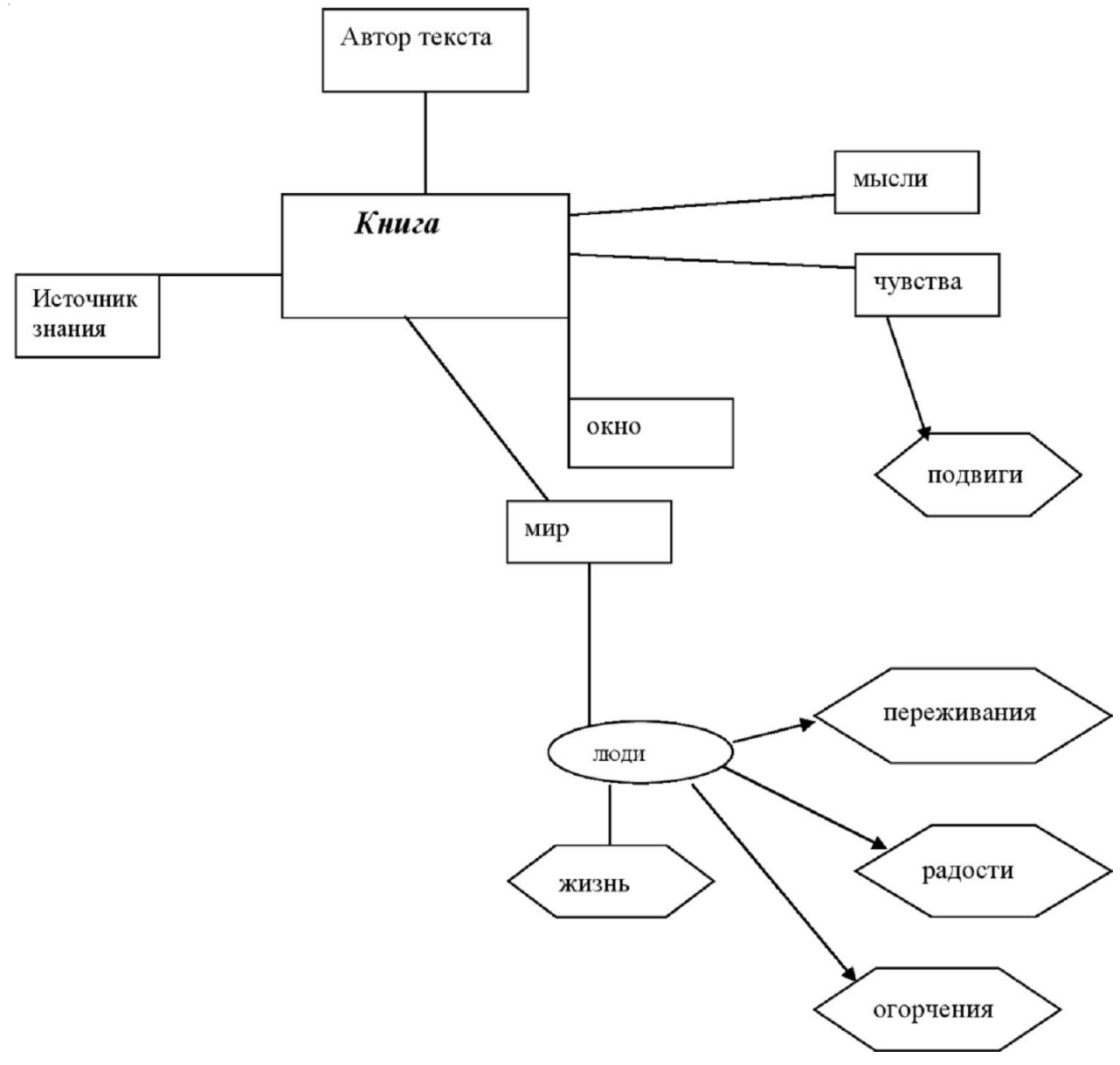

Рис. 7. Граф № 2.3

Таблииа 2

\section{Количественная характеристика вторичных текстов активного порождения}

\begin{tabular}{|l|c|c|c|}
\cline { 1 - 2 } \multicolumn{1}{|c|}{ № граф выборки } & Граф & Граф & Граф \\
\cline { 1 - 1 } Уровень структуры текста & $\mathbf{2 . 1}$ & $\mathbf{2 . 2}$ & $\mathbf{2 . 3}$ \\
\hline Уровень подтем & $67 \%$ & $67 \%$ & $67 \%$ \\
\hline Уровень субподтем & $10 \%$ & $10 \%$ & $10 \%$ \\
\cline { 1 - 3 } Уровень микротем & $0 \%$ & $0 \%$ & $20 \%$ \\
\hline
\end{tabular}

Итак, во вторичных текстах активного порождения прослеживается существенное изменение иерархии во внутренней структуре. Многие субподтемы перестроились в подтемы, а микротемы раскрыты в единичных вторичных текстах. Сохранение подтем по сравнению с контрольным графом можно отметить лишь у $67 \%$ испытуемых, а на уровне субподтем - у $10 \%$.

3.3. Экспериментальный метод подтвердил предположение о том, что изменение иерархии внутренней структуры текста является одним из механизмов смыслообразования, то есть перестройка на уровне подтем, субподтем и микротем показывает, как и что испытуемый понимал, пытаясь воспроизвести исходный текст. Сравнивая графы исходного и вторичных текстов, мы обнаружили, что при пассивном порождении вторичного текста уровень подтем представлен достаточно полно - от $67 \%$ до $88 \%$ текстов сохраняют подтемы исходного текста. При активном порождении в $67 \%$ текстов сохраняются исходные подтемы. Это можно объяснить тем, что активное порождение текста предлагает относительную свободу понимания и смысл текста формируется не на основе жестко заданной структуры, а на основе предтекстовой 
Н.В. Матвеева. Механизмы формирования содержания и смысла текста в процессе его восприятия

пресуппозиции и внутритекстовой импликации. Мы отмечаем существенную перестройку иерархии структуры содержания на уровне субподтем и микротем, эксплицирующую образование смысла, вкладываемого испытуемыми во вторичный текст.

При относительно свободном порождении вторичного текста испытуемые передавали свое индивидуальное понимание, толкование содержания, используя стратегию перестройки иерархии структуры содержания текста. Реализация данной стратегии может рассматриваться как механизм смыслообразования в противоположность стратегии сохранения иерархии структуры содержания механизму образования содержания.

\section{4}

Помимо сохранения либо изменения иерархии в структуре содержания текста, инструментом исследования механизмов смыслообразования служит анализ лексики, используемой испытуемыми во вторичном тексте. В ходе эксперимента мы ставили задачу сравнить употребление ключевых слов в Т2 по отношению к Т1, то есть проследить, какие изменения были внесены в синонимический ряд ключевых слов. Например, использованный в исходном тексте глагол испытать «изведать на опыте, пережить» заменен автором вторичного текста на глагол чувствовать «испытывать какое-нибудь чувство», «уметь воспринимать, понимать», содержащий коннотативный компонент «изведать на опыте, пережить какое-нибудь чувство».

Синонимические замены обнаруживают индивидуальное восприятие испытуемыми содержания прочитанного, в частности эмоциональное отношение, оценку, собственное толкование (особый вместо неведомый; советую вместо говорю каждому; делать ясным, понятным вместо наполнять смыслом; запутанные мысли вместо путаница; высота вместо лучшее), то есть отражают процессы смыслообразования.

Таким образом, в результате анализа экспериментальных данных исследования иерархии денотатов во внутренней (смысловой) структуре исходного и вторичных текстов и синонимического ряда ключевых слов исходного и вторичных текстов установлено, что механизм формирования содержания состоит в сохранении иерархии в отношениях денотатов в структуре содержания Т2 по отношению к структуре Т1; механизмы образования смысла включают изменение иерархии (перестройку на уровне подтем, субподтем, микротем) в структуре содержания Т2 и стратегию использования синонимов с новыми коннотациями.

Полученные результаты могут быть уточнены и дополнены в ходе исследования индивидуальных стратегий реципиентов, воспринимающих различные типы текстов. Это необходимо для выявления соотношения индивидуальных стратегий с механизмами смыслообразования, с одной стороны, и с типом текста - с другой, для решения столь сложной проблемы, как моделирование процессов понимания текста.

\section{СПИСОК ЛИТЕРАТУРЫ}

Жинкин, Н. И. О кодовых переходах во внутренней речи / Н. И. Жинкин // Вопросы языкознания. - 1964. - № 6. - С. 26-38.

Караулов, Ю. Н. Русский язык и языковая личность / Ю. Н. Караулов. - М. : Наука, 1987. - 262 с.

Новиков, А. И. Семантика текста и ее формализация / А. И. Новиков. - М. : Наука, 1983. -216 с.

Новиков, А. И. Текст, смысл и проблемная ситуация / А. И. Новиков // Вопросы филологии. 1999. - № 3. - С. 43-48.

Пешкова, Н. П. Исследование механизмов смыслообразования в процессах восприятия и понимания письменного учебного текста / Н. П. Пешкова, Н. В. Матвеева // Лингводидактические и культурологические аспекты обучения иностранным языкам. - Уфа : УГАТУ, 2003. - С. 121-125.

Пешкова, Н. П. Семантика и смысл текста: >, <, $=$,\#? (Экспериментальный подход к теоретическим проблемам) / Н. П. Пешкова // Вестник Челябинского государственного университета. Филология. Искусствоведение. -2015. - № 15 (370). - С. 69-77.

\section{REFERENCES}

Zhinkin N.I. O kodovykh perekhodakh vo vnutrenney rechi [About Code Transformations in the 
Inner Speech]. Voprosy yazykoznaniya, 1964, no. 6, pp. 26-38.

Karaulov Yu.N. Russkiy yazyk i yazykovaya lichnost [The Russian Language and Language Personality]. Moscow, Nauka Publ., 1987. 262 p.

Novikov A.I. Semantika teksta $i$ ee formalizatsiya [Text Semantics and Its Formalization]. Moscow, Nauka Publ., 1983. 216 p.

Novikov A.I. Tekst, smysl i problemnaya situatsiya [Text, Meaning and Problem Situation]. Voprosy filologii, 1999, no. 3, pp. 43-48.

Peshkova N.P. Issledovanie mekhanizmov smysloobrazovaniya $\mathrm{v}$ protsessakh vospriyatiya $\mathrm{i}$ ponimaniya pismennogo uchebnogo teksta
[Research of Sense Forming Mechanisms in the Processes of Perception and Understanding of the Written Exercise Text]. Lingvodidakticheskie $i$ kulturologicheskie aspekty obucheniya inostrannym yazykam [Linguo-Didactic and Culturological Aspects of Teaching Foreign Languages]. Ufa, UGATU Publ., 2003, pp. 121-125. Peshkova N.P. Semantika i smysl teksta: $>,<,=$, \#? (Eksperimentalnyy podkhod $\mathrm{k}$ teoreticheskim problemam) [Semantics and Meaning of the Text: $>,<$, $=$, \#? (Experiental Approach to the Theoretical Problems)] Vestnik Chelyabinskogo gosudarstvennogo universiteta. Filologiya. Iskusstvovedenie, 2015, no. 15 (370), pp. 69-77.

\section{Information About the Author}

Nataliya V. Matveeva, Candidate of Sciences (Philology), Associate Professor, Head of Department the Germanic Languages, Sterlitamak Branch of the Bashkir State University, Prosp. Lenina, 49, 453120 Sterlitamak, Republic of Bashkortostan, Russian Federation, elivic@mail.ru, http://orcid.org/0000-00030301-5905.

\section{Информация об авторе}

Наталья Васильевна Матвеева, кандидат филологических наук, доцент, заведующая кафедрой германских языков, Стерлитамакский филиал Башкирского государственного университета, просп. Ленина, 49, 453120 г. Стерлитамак, Республика Башкортостан, Российская Федерация, elivic@mail.ru, http://orcid.org/0000-0003-0301-5905. 